
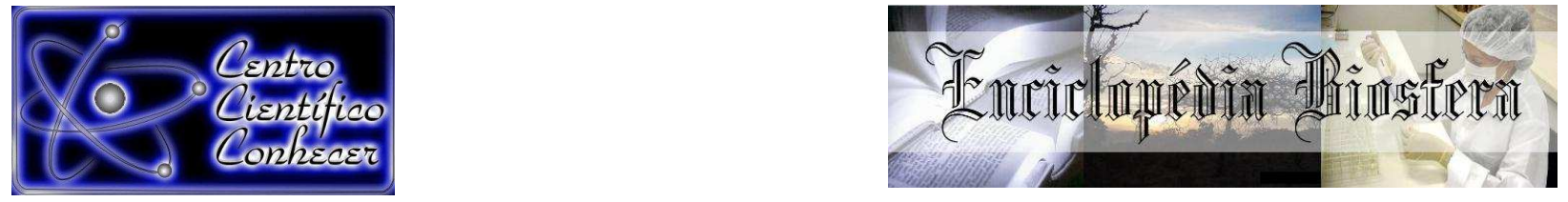

\title{
ADERÊNCIA DO PÓ DE BASALTO À SEMENTES DE FEIJÃO MIÚDO UTILIZANDO COMO ADESIVO COLA PVA
}

Ricardo Batista Job ${ }^{1}$, Carlos Eduardo da Silva Pedroso², Gilberto Antônio Peripolli Bevilaqua $^{3}$, Gabriela Berguenmaier de Olanda ${ }^{4}$, Régis Araújo Pinheiro ${ }^{5}$

${ }^{1}$ Doutorando em Agronomia pelo Programa de Pós-Graduação em Sistemas de Produção Agrícola Familiar da Universidade Federal de Pelotas, Capão do Leão, Brasil (ricardo_job@yahoo.com.br)

${ }^{2}$ Discente do Curso de Agronomia da Universidade Federal de Pelotas, Capão do Leão, Brasil

${ }^{3}$ Pesquisador da Embrapa Clima Temperado, Capão do Leão, Brasil

${ }^{4}$ Doutoranda em Agronomia pelo Programa de Pós-Graduação em Sistemas de Produção Agrícola Familiar da Universidade Federal de Pelotas, Capão do Leão, Brasil

${ }^{5}$ Mestrando em Agronomia pelo Programa de Pós-Graduação em Sistemas de Produção Agrícola Familiar da Universidade Federal de Pelotas, Capão do Leão, Brasil

Recebido em: 02/10/2017 - Aprovado em: 21/11/2017 - Publicado em: 05/12/2017 DOI: 10.18677/EnciBio_2017B1

O objetivo do trabalho foi avaliar a aderência do recobrimento com agromineral basalto em sementes de feijão miúdo (Vigna unguiculata (L.) Walp.) e os efeitos do adesivo a base de acetado de polivinila (PVA) sobre a germinação das sementes. $O$ experimento ocorreu na Estação Terras Baixas da Embrapa Clima Temperado, Capão do Leão/RS, Brasil. Foram utilizadas sementes de feijão miúdo recobertas com agromineral basalto, na forma de pó ultrafino, utilizando como adesivo diferentes diluições de PVA. As diluições utilizadas corresponderam a 0,2; 0,4; 0,6; 0,$8 ; 1,0 ; 1,2 ; 1,4 ; 1,6 ; 1,8$ e 2,0ml de PVA, complementado com água destilada até obter volume total de $2,0 \mathrm{ml}$ de mistura. $\mathrm{O}$ fator $\mathrm{A}$ foi concentração do adesivo PVA: 10, 20, 30, 40, 50, 60, 70, 80, 90 e 100\%; o fator B foi: com e sem recobrimento. As variáveis observadas foram: germinação em substrato de vermiculita a partir de contagens aos cinco e oito dias após a semeadura e; teste de aderência do recobrimento das sementes a partir da simulação de semeadura com saraquá. $A$ diluição do adesivo a base de PVA influencia na quantidade de pó de basalto aderido às sementes. A medida que o adesivo é diluído aumenta a quantidade de pó de basalto no recobrimento das sementes. A simulação de semeadura com saraquá foi um bom teste sobre a aderência do recobrimento das sementes. A medida que aumenta a concentração do PVA no adesivo ocorre menor perda de pó de basalto nas sementes recobertas.

PALAVRAS- CHAVE: acetato de polivinila, agromineral, pó de rocha. 


\title{
ADERENCE OF BASALT POWDER IN COWPEA SEED UTILIZING PVA AS ADESIVE
}

\begin{abstract}
The objective of this work was to evaluate the adhesion of the coating with basalt agromineral on cowpea seeds (Vigna unguiculata (L.) Walp.) and the effects of the adhesive based on polyvinyl acetate (PVA) on germination. The experiment occurred out at Experimental area of Lowland Agricultural Research Station of Embrapa Temperate Climate, Capão do Leão/RS, Brazil. Cowpea seeds coated with basalt agromineral in the form of ultrafine powder were used, using different dilutions of PVA as an adhesive. The dilutions used corresponded to $0.2,0.4,0.6,0.8,1.0,1,2$, $1.4,1.6,1.8$ and $2.0 \mathrm{ml}$ of PVA, completed with distilled water until a total volume of $2.0 \mathrm{ml}$ of the mixture was obtained. Factor $A$ was the concentration of the PVA adhesive: $10,20,30,40,50,60,70,80,90$ and 100\%; the factor B was: with and without coating. The variables observed were: germination in vermiculite substrate from counts at five and eight days after sowing and; adhesion test of the seed coatings from the sowing simulation with saraquá. Dilution of the PVA-based adhesive influences the amount of basalt powder adhered to the seeds. As the adhesive is diluted the amount of basalt powder increases in the coating of the seeds. The simulation of sowing with saraquá was a good test on the adherence of seeds coating. As the PVA concentration in the adhesive increases, smaller loss of basalt powder occurs in the coated seeds.
\end{abstract}

KEYWORDS: polyvinyl acetate, agromineral, rock dust.

\section{INTRODUÇÃO}

A constituição rochosa da litosfera é fonte de muitos elementos importantes para o desenvolvimento das plantas, que ao sofrer os processos físicos, químicos e biológicos do intemperismo, passa a distribuí-los espacialmente, dando origem aos minerais do solo (SIMÃO, 2012; ARTUR et al., 2014).

A utilização de subprodutos da britagem de rochas ou agrominerais, como são determinados pela Lei 12.890/13 (BRASIL, 2013), quando utilizados na agricultura via solo, na fertilização de plantas ou no tratamento de sementes, atuam sobre os componentes de rendimento de culturas como como feijão miúdo (Vigna unguiculata (L.) Walp.), trigo (Triticum sativum L.), amendoim (Arachis hypogaea L.), feijão comum (Phaseolus vulgaris L.) e soja (Glycine max L.), (TAVARES et al., 2013; CRUSCIOL et al., 2013; COUTINHO et al., 2014).

O basalto é uma rocha ígnea, intrusiva de coloração escura, granulometria grossa e presença de minerais máficos, de presença abundante no Brasil e que possui macro e microelementos importantes para a biologia do solo e nutrição das plantas (WESTHEIMER, 2006).

O pó de basalto combinado a outros compostos orgânicos como esterco bovino, melhora as propriedades do solo e aumenta os índices de pH em função das quantidades de óxido de cálcio $(\mathrm{CaO})$ e óxido de magnésio $(\mathrm{MgO})$, liberando elementos como Mg, $\mathrm{K}$ e Si trocável, importantes em sistemas produtivos (SILVA et al., 2012; MELO et al., 2012).

Em meio ácido o basalto libera elementos. A ação de ácidos orgânicos sobre este mineral, a exemplo da vinhaça - subproduto do setor sucroalcooleiro, pode promover a liberação de cátions trocáveis presentes neste mineral e favorecer a disponibilidade de elementos às plantas (LOPES et al., 2013). Por isso torna-se um 
agromineral importante em sistemas de produção orgânica, pois a sua combinação variada de elementos presentes na sua composição litoquimica permite participar de forma equilibrada na nutrição de plantas, com resultados satisfatórios em cultivos como o morangueiro e couve-chinesa (CAMARGO et al., 2012; TESSARO et al., 2013).

Além de atuar sobre os componentes de rendimento das culturas, os agrominerais também podem ser utilizados no controle biológico de insetos praga, onde atuam como barreira física dificultando seu deslocamento na massa de sementes e grãos armazenados e consequentemente sua proliferação (JAIROCE et al., 2016).

O basalto utilizado na forma de pó ultrafino também pode melhorar 0 desempenho fisiológico em sementes de arroz quando utilizado no recobrimento das sementes, logo nos primeiros períodos de armazenamento (EBERHARDT et al., 2015).

Tendo o feijão miúdo (Vigna unguiculata (L.) Walp) como uma cultura importante na região costeira do Litoral Sul do Rio Grande do Sul onde é utilizado como cobertura morta, em recuperação de solos degradados e na alimentação animal (OLIVEIRA et al., 2014), cujos teores de proteína bruta nas folhas variar de 16 a $26 \%$ entre as fases de pré-floração à floração plena (BEVILAQUA et al., 2013), justifica-se o tratamento de suas sementes com agrominerais em função da vulnerabilidade ao ataque de insetos e fungos quando armazenadas.

Dentro deste contexto, o objetivo do trabalho foi avaliar a aderência do recobrimento com agromineral basalto em sementes de feijão miúdo (Vigna unguiculata (L.) Walp.) e os efeitos do adesivo a base de acetado de polivinila (PVA) sobre a germinação.

\section{MATERIAL E MÉTODOS}

O experimento foi conduzido na Estação Terras Baixas da Embrapa Clima

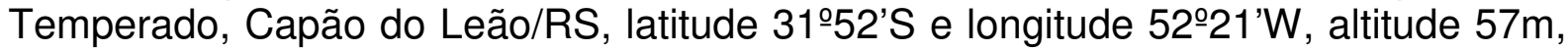
no ano de 2014. O clima é do tipo Cfa conforme a classificação de Köppen-Geiger (GOTTSCHALL et al., 2012).

Padronização das sementes: Foram utilizadas sementes de feijão miúdo, cultivar Amendoim, safra 2012/2013, cedidas pela Cooperativa dos Agricultores Familiares Nortense - COAFAN, de São José do Norte/RS. As sementes foram classificadas quanto a largura e espessura em peneiras de furos redondo e oblongo de modo que foram utilizadas apenas as sementes retidas nas peneiras de malha $6 \mathrm{~mm}$. Foi determinado o peso de 1.000 sementes, seguindo a metodologia padrão determinada pelas Regras para Análise de Sementes (Brasil, 2009). O peso de 1.000 sementes utilizadas neste experimento foi de $183,5 \mathrm{~g}$. As sementes foram divididas em 21 lotes de $100 \mathrm{~g}$, sendo um destes considerado como testemunha sem qualquer tratamento.

Diluição do adesivo: Como adesivo foi utilizado acetato de polivinila (PVA), diluído de tal forma que o volume final da solução fosse composto por partes equivalentes de PVA e água destilada, em $\mathrm{ml}$ de PVA/ml de água, nas proporções 1:9; 2:8; 3:7; $4: 6 ; 5: 5 ; 6: 4 ; 7: 3 ; 8: 2 ; 9: 1$ e 10:0. Estas foram as diluições do adesivo utilizado nas sementes, correspondentes a 10, 20, 30, 40,50,60,70, 80, 90 e 100\% PVA. A dosagem destas diluições utilizada nas sementes foi de $2 \mathrm{ml} / 100 \mathrm{~g}$ de semente, homogeneizadas manualmente em como de Becker utilizando bastão de vidro. 
Tratamentos: Cada diluição do adesivo foi aplicada em duas porções de $100 \mathrm{~g}$ de sementes. Deste total de 20 porções, apenas 10 receberam o recobrimento com o agromineral basalto. As sementes receberam pó de basalto até ficarem completamente recobertas. A homogeneização das sementes + adesivo ao pó de basalto foi realizada em bandejas de polietileno. Quando todas as sementes estavam recobertas foram colocadas em peneiras para retirar o excesso de pó não aderido às sementes. A Tabela 1 descreve o arranjo de tratamentos com diferentes diluições do adesivo a base de PVA e pó de basalto.

TABELA 1. Tratamentos com diferentes diluições de adesivo a base de acetato de polivinila (PVA) e água em sementes de feijão miúdo com e sem recobrimento com pó do agromineral basalto.

\begin{tabular}{lcccc}
\hline $\begin{array}{l}\text { Tipo de } \\
\text { recobrimento }\end{array}$ & Abreviatura & $\begin{array}{c}\text { Diluição do } \\
\text { adesivo } \\
(\%)\end{array}$ & $\begin{array}{c}\text { Proporção } \\
\text { PVA+água } \\
\text { (ml PVA/ml } \\
\text { água) }\end{array}$ & Tratamentos \\
\hline Basalto & BAS & 10 & $1: 9$ & BAS 10 \\
Basalto & BAS & 20 & $2: 8$ & BAS 20 \\
Basalto & BAS & 30 & $3: 7$ & BAS 30 \\
Basalto & BAS & 40 & $4: 6$ & BAS 40 \\
Basalto & BAS & 50 & $5: 5$ & BAS 50 \\
Basalto & BAS & 60 & $6: 4$ & BAS 60 \\
Basalto & BAS & 70 & $7: 3$ & BAS 70 \\
Basalto & BAS & 80 & $8: 2$ & BAS 80 \\
Basalto & BAS & 90 & $9: 1$ & BAS 90 \\
Basalto & BAS & 100 & $10: 0$ & BAS 100 \\
Sem recobrimento & SRC & 10 & $1: 9$ & SRC 10 \\
Sem recobrimento & SRC & 20 & $2: 8$ & SRC 20 \\
Sem recobrimento & SRC & 30 & $3: 7$ & SRC 30 \\
Sem recobrimento & SRC & 40 & $4: 6$ & SRC 40 \\
Sem recobrimento & SRC & 50 & $5: 5$ & SRC 50 \\
Sem recobrimento & SRC & 60 & $6: 4$ & SRC 60 \\
Sem recobrimento & SRC & 70 & $7: 3$ & SRC 70 \\
Sem recobrimento & SRC & 80 & $8: 2$ & SRC 80 \\
Sem recobrimento & SRC & 90 & $9: 1$ & SRC 90 \\
Sem recobrimento & SRC & 100 & $10: 0$ & SRC 100 \\
Testemunha & TES & Sem adesivo & - & TES \\
\hline
\end{tabular}

O agromineral utilizado neste trabalho pertence ao Banco de Agrominerais da Embrapa Clima Temperado. A rocha foi britada (moída), passada em peneira de 140 mesh $(0,105 \mathrm{~mm})$ e seca em estufa de convecção mecânica (ar forçado) à $55^{\circ} \mathrm{C} \pm 5^{\circ} \mathrm{C}$ por 72 horas. Esta rocha foi submetida a análise litoquímica no ACME Analytical Laboratories Ltda, Vancouver, Canadá e o teor total de elementos determinado pelo método ICP (Inductively Coupled Plasma), (Tabela 2). 
TABELA 2. Análise litoquimica do agromineral basalto (BAS)

\begin{tabular}{ccccccccc}
\hline Elemento & Unidade & BAS & \multicolumn{2}{l}{ Elemento } & Unidade & \multicolumn{2}{c}{$\mathrm{BAS}$} & \multicolumn{2}{c}{ Elemento } & Unidade & $\mathrm{BAS}$ \\
\hline $\mathrm{SiO}_{2}$ & $\%$ & 65,91 & $\mathrm{Ga}$ & $\mathrm{ppm}$ & 17,8 & $\mathrm{Dy}$ & $\mathrm{ppm}$ & 7,94 \\
$\mathrm{Al}_{2} \mathrm{O}_{3}$ & $\%$ & 12,53 & $\mathrm{Hf}$ & $\mathrm{ppm}$ & 7,7 & $\mathrm{Ho}$ & $\mathrm{ppm}$ & 1,6 \\
$\mathrm{Fe}_{2} \mathrm{O}_{3}$ & $\%$ & 6,94 & $\mathrm{Nb}$ & $\mathrm{ppm}$ & 21,9 & $\mathrm{Er}$ & $\mathrm{ppm}$ & 4,35 \\
$\mathrm{MgO}$ & $\%$ & 1,42 & $\mathrm{Rb}$ & $\mathrm{ppm}$ & 145,5 & $\mathrm{Tm}$ & $\mathrm{ppm}$ & 0,68 \\
$\mathrm{CaO}$ & $\%$ & 3,58 & $\mathrm{Sn}$ & $\mathrm{ppm}$ & 5 & $\mathrm{Yb}$ & $\mathrm{ppm}$ & 4,1 \\
$\mathrm{Na}_{2} \mathrm{O}$ & $\%$ & 3,51 & $\mathrm{Sr}$ & $\mathrm{ppm}$ & 154,8 & $\mathrm{Lu}$ & $\mathrm{ppm}$ & 0,62 \\
$\mathrm{~K}_{2} \mathrm{O}$ & $\%$ & 3,48 & $\mathrm{Ta}$ & $\mathrm{ppm}$ & 1,8 & $\mathrm{Mo}$ & $\mathrm{ppm}$ & 1,4 \\
$\mathrm{TiO}_{2}$ & $\%$ & 1,04 & $\mathrm{Th}$ & $\mathrm{ppm}$ & 13,4 & $\mathrm{Cu}$ & $\mathrm{ppm}$ & 97,4 \\
$\mathrm{P}_{2} \mathrm{O}_{5}$ & $\%$ & 0,32 & $\mathrm{U}$ & $\mathrm{ppm}$ & 4,5 & $\mathrm{~Pb}$ & $\mathrm{ppm}$ & 3 \\
$\mathrm{MnO}$ & $\%$ & 0,14 & $\mathrm{~V}$ & $\mathrm{ppm}$ & 90 & $\mathrm{Zn}$ & $\mathrm{ppm}$ & 47 \\
$\mathrm{Cr}_{2} \mathrm{O}_{3}$ & $\%$ & 0,006 & $\mathrm{~W}$ & $\mathrm{ppm}$ & 36,6 & $\mathrm{Ni}$ & $\mathrm{ppm}$ & 4,5 \\
$\mathrm{Ni}$ & $\mathrm{ppm}$ & $<20$ & $\mathrm{Zr}$ & $\mathrm{ppm}$ & 265,7 & $\mathrm{As}$ & $\mathrm{ppm}$ & 2,1 \\
$\mathrm{Sc}$ & $\mathrm{ppm}$ & 17 & $\mathrm{Y}$ & $\mathrm{ppm}$ & 41,5 & $\mathrm{Cd}$ & $\mathrm{ppm}$ & $<0.1$ \\
$\mathrm{TOT} / \mathrm{C}$ & $\%$ & 0,05 & $\mathrm{La}$ & $\mathrm{ppm}$ & 39,8 & $\mathrm{Sb}$ & $\mathrm{ppm}$ & $<0.1$ \\
$\mathrm{TOT} / \mathrm{S}$ & $\%$ & $<0.02$ & $\mathrm{Ce}$ & $\mathrm{ppm}$ & 82,7 & $\mathrm{Bi}$ & $\mathrm{ppm}$ & 0,1 \\
$\mathrm{LOI}$ & $\%$ & 0,9 & $\mathrm{Pr}$ & $\mathrm{ppm}$ & 10,19 & $\mathrm{Ag}$ & $\mathrm{ppm}$ & $<0.1$ \\
$\mathrm{Sum}$ & $\%$ & 99,76 & $\mathrm{Nd}$ & $\mathrm{ppm}$ & 40,9 & $\mathrm{Au}$ & $\mathrm{ppb}$ & $<0.5$ \\
$\mathrm{Ba}$ & $\mathrm{ppm}$ & 588 & $\mathrm{Sm}$ & $\mathrm{ppm}$ & 8,75 & $\mathrm{Hg}$ & $\mathrm{ppm}$ & 0,02 \\
$\mathrm{Be}$ & $\mathrm{ppm}$ & 3 & $\mathrm{Eu}$ & $\mathrm{ppm}$ & 1,82 & $\mathrm{Tl}$ & $\mathrm{ppm}$ & $<0.1$ \\
$\mathrm{Co}$ & $\mathrm{ppm}$ & 17,8 & $\mathrm{Gd}$ & $\mathrm{ppm}$ & 8,17 & $\mathrm{Se}$ & $\mathrm{ppm}$ & $<0.5$ \\
$\mathrm{Cs}$ & $\mathrm{ppm}$ & 5,5 & $\mathrm{~Tb}$ & $\mathrm{ppm}$ & 1,37 & & & \\
\hline
\end{tabular}

Teste de germinação: Foi realizada a semeadura em substrato de vermiculita, 24 horas após o recobrimento das sementes. Foram semeadas 50 sementes em bandejas de polietileno de dimensões $55 \mathrm{~cm} \times 33 \mathrm{~cm}$, dispostas em cinco linhas com dez sementes. Cada bandeja representou uma repetição. $O$ delineamento experimental foi inteiramente ao acaso, com quatro repetições. Foram consideradas sementes germinadas aquelas capaz de originar plântulas sadias, cuja emergência na superfície da vermiculita estabeleceu o movimento epígeo perfeito, permitindo observar os cotilédones entreabertos expondo as folhas cotiledonares. As contagens de sementes germinadas ocorreram aos cinco e oito dias após a semeadura. $\mathrm{O}$ experimento foi conduzido em casa de vegetação.

Teste da aderência do recobrimento: Para testar a aderência do pó de basalto às sementes foi simulado uma semeadura utilizando máquina de saraquá (matraca). Foram selecionadas 300 sementes ao acaso de cada porção de semente, pesadas em balança analítica de precisão $0,0001 \mathrm{~g}$ e colocadas na máquina de saraquá. Foram dadas 100 investidas com o saraquá sobre uma bandeja de polietileno, recolhidas as sementes e pesadas novamente para quantificar as perdas do material recobridor.

Os dados foram analisados utilizando software estatístico WinStat $1.0{ }^{\circledR}$. Foi realizada a análise de variância, comparação de médias pelo teste de Tukey e regressões polinomiais, todos com nível de significância de $5 \%(p<0,05)$. 


\section{RESULTADOS E DISCUSSÃO}

A quantidade de pó de basalto aderido às sementes foi variável em função das diluições do adesivo a base de PVA utilizado no recobrimento das sementes de feijão miúdo. O coeficiente de determinação $R^{2}$ demonstrou que $96,8 \%$ da variação na aderência de pó de basalto às sementes é explicada pela curva determinada pelo modelo polinomial ajustado (Figura 1). Da mesma forma apenas 3,2\% desta variação ainda permaneceu não explicada.

A medida que $o$ adesivo a base de PVA foi diluído, diminuiu sua viscosidade e aumentou o acréscimo de pó de basalto nas sementes de feijão miúdo. Inversamente, quanto mais concentrado o adesivo, ou seja, mais viscoso em função da concentração de PVA em relação a água, menos pó de basalto foi aderido à superfície das sementes (Figura 1).

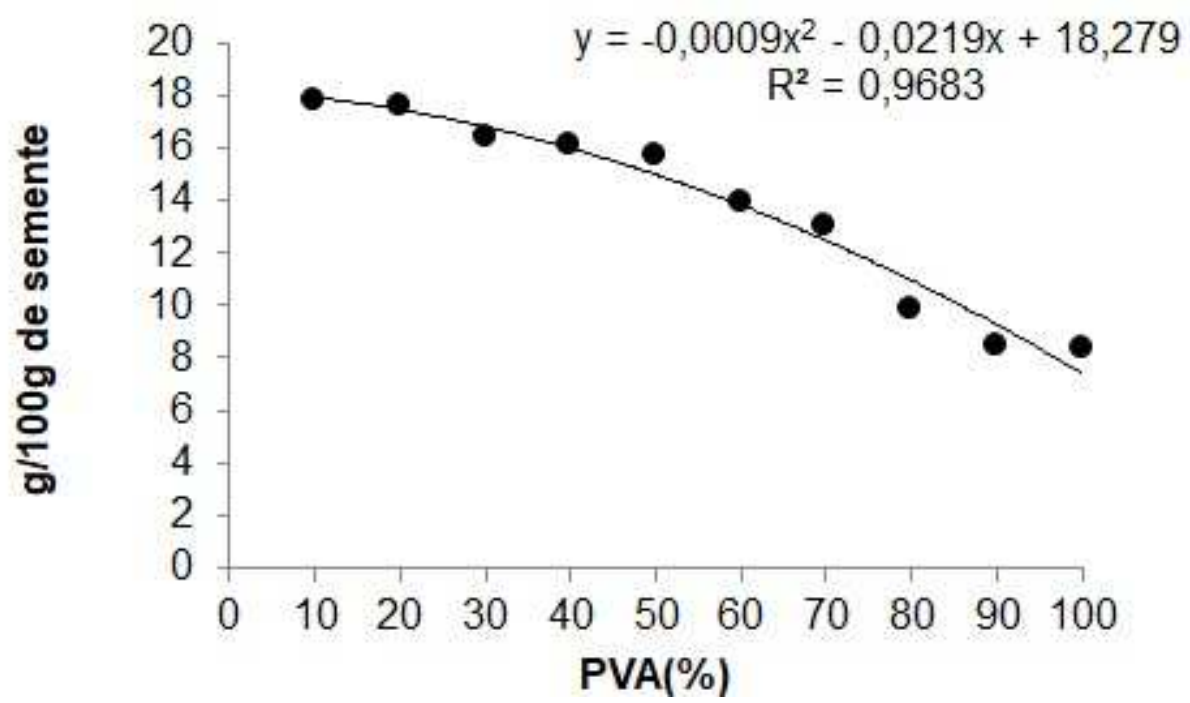

FIGURA 1. Quantidade de agromineral aderido às sementes em relação as diluições do adesivo a base de acetato de polivinila (PVA).

Isso é possível porque nas maiores diluições do adesivo (PVA+água) ocorre mais participação de água na mistura. A exemplo do PVA 10\% significa dizer que em $2 \mathrm{ml}$ de adesivo utilizado no recobrimento das sementes, $0,2 \mathrm{ml}$ é PVA e $1,8 \mathrm{ml}$ é água, seguindo a metodologia adotada na confecção do adesivo (Tabela 1). Como o agromineral utilizado no recobrimento das sementes é um pó ultrafino (partículas com $\varnothing<0,105 \mathrm{~mm}$ ), o teor de água do adesivo contribui para que ocorra maior incremento de pó de basalto momentaneamente às sementes de feijão miúdo, agregando maior peso final das porções semente+adesivo+pó de basalto. O pó de basalto agregado às sementes de feijão miúdo recobertas a partir do PVA mais diluído pode minimizar os efeitos do teor de água contida no adesivo que estas sementes recebem, por possuir grande participação de dióxido de silício $\left(\mathrm{SiO}_{2}\right)$ em sua contribuição litoquimica e por este ser considerado um elemento que retém umidade (FONTES et al., 2012).

As sementes de feijão miúdo que recebem adesivo PVA mais concentrado agregam e perdem menos pó de basalto do recobrimento em relação as sementes recobertas a partir de adesivo mais diluído. $O$ teste realizado a partir da simulação 
de semeadura com saraquá para determinar a aderência do pó de basalto às sementes demonstrou este efeito. A Figura 2 mostra o modelo ajustado para a perda de material utilizado no recobrimento em função da diluição do adesivo. $O$ Coeficiente de determinação $R^{2}$ demonstra que $93,5 \%$ da variação do peso das sementes após o teste com saraquá é explicado pela curva determinada pelo modelo. É possível observar que ocorre menor perda de material do recobrimento quanto mais concentrado é o adesivo PVA utilizado no processo. Nas altas diluições o pó de basalto fica aderido às sementes com baixa resistência, muito em função da água presente no adesivo do que do PVA. Isto faz com que a camada de recobrimento se desagregue com maior facilidade quando a semente sofre atrito com outro corpo sólido.

- Antes

$$
\begin{gathered}
y=-0,0005 x^{2}-0,0121 x+65,113 \\
R^{2}=0,9683
\end{gathered}
$$

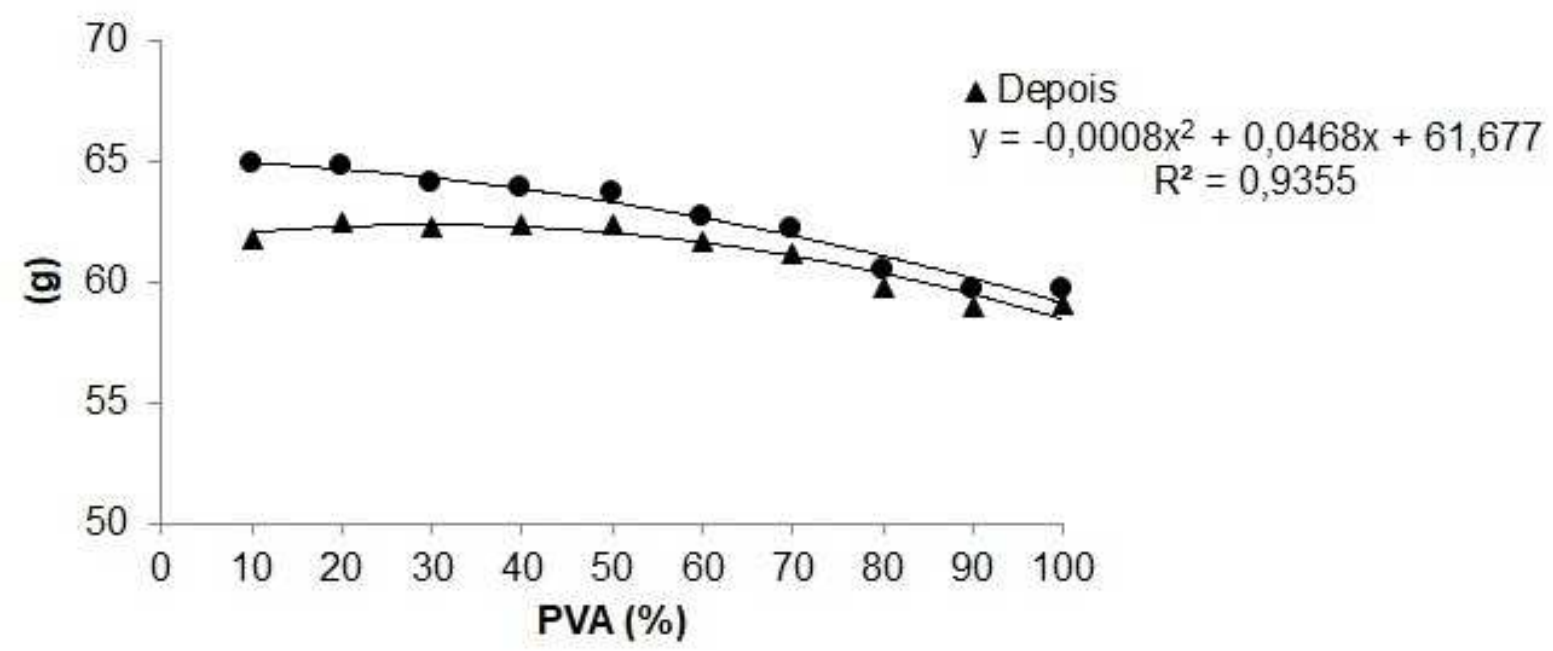

FIGURA 2. Peso das 300 sementes + adesivo + pó de basalto: A. antes do teste com saraquá e; B. depois do teste com saraquá.

A quantidade de pó de basalto que se desprendeu das sementes recobertas está demonstrada da Figura 3. O modelo mostra que utilizando adesivo a base de PVA 99\% ocorre a menor perda de agromineral das sementes - 0,54g de agromineral, neste tipo de teste com saraquá. A maior perda é quando é utilizado PVA $10 \%$, chegando a $2,88 \mathrm{~g}$ de agromineral. O Coeficiente de determinação $\mathrm{R}^{2}$ demonstra que $97,8 \%$ da variação na perda de agromineral das sementes após o teste com saraquá é explicado pela curva determinada pelo modelo. 


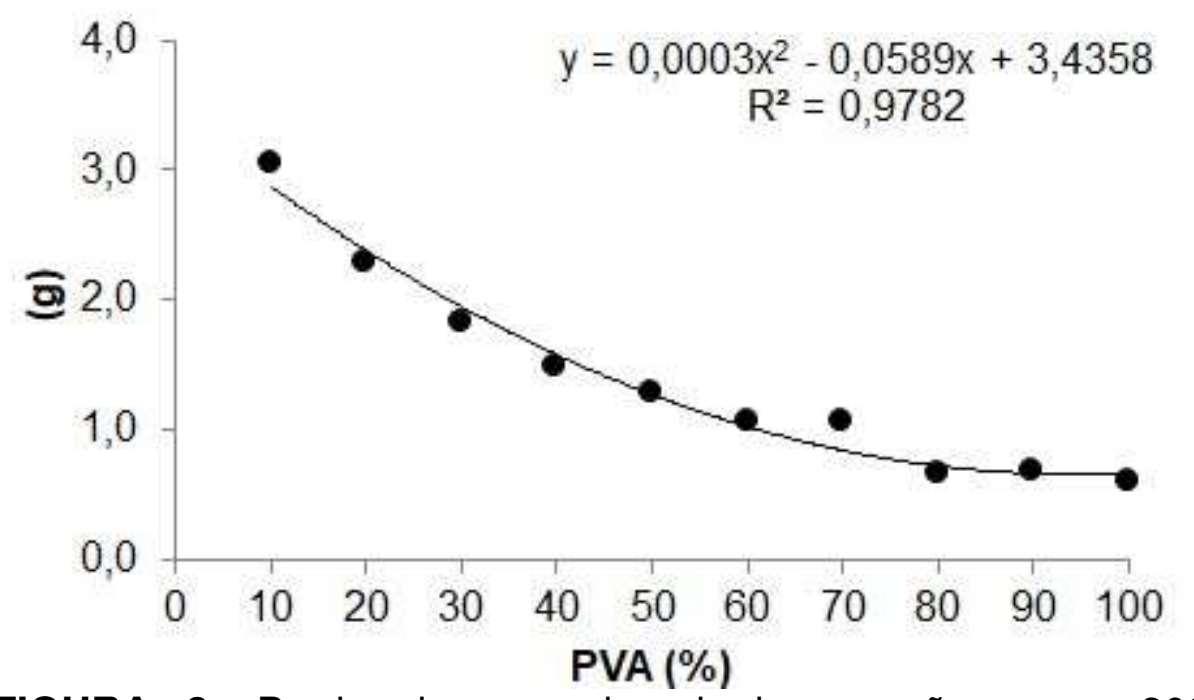

FIGURA 3. Perda de agromineral das porções com 300 sementes após o teste com saraquá, em relação as diluições do adesivo.

Em termos percentuais, a diferença entre o que a semente agrega de pó de basalto no recobrimento e o que perde após a simulação da semeadura com saraquá é possível observar no modelo estabelecido na Figura 4. O modelo mostra que o menor percentual de perda do recobrimento ocorre quando é utilizada diluição de PVA $78 \%$, chegando a 12,5\%. Quando é utilizado adesivo PVA 10\%, as perdas de pó de basalto utilizado no recobrimento das sementes de feijão miúdo chegam a $29,3 \%$. O coeficiente de determinação $R^{2}$ deste modelo explica $95,3 \%$ da variação nos percentuais de perda do recobrimento das sementes após o teste com saraquá.

A proporção de adesivo utilizado na mistura cimentante é importante para manter o material recobridor aderido às sementes, evitando perdas dos tratamentos. Conceição e Vieira (2008) utilizaram diferentes proporções de PVA no recobrimento de sementes de milho (Zea mays L.) e também observaram que ocorreu menor perda do material do recobrimento a medida que aumentaram as proporções de adesivo. 


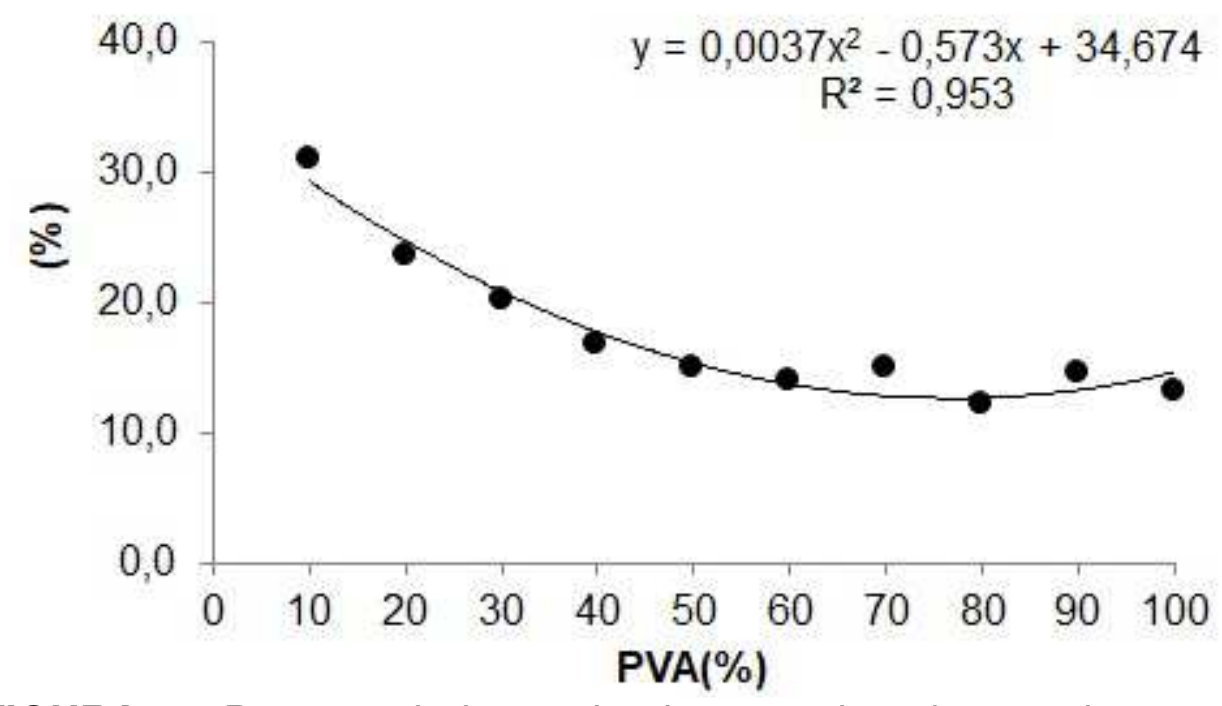

FIGURA 4. Percentual de perda de agromineral em relação a concentração do adesivo

As comparações pareadas de médias para a variável resposta germinação não demonstraram diferença significativa, aos cinco e oito dias após a semeadura, quando fixados os fatores com e sem pó de basalto e as diluições do adesivo PVA, como mostra a Tabela 3.

TABELA 3. Percentual de germinação aos cinco e aos oito dias após a semeadura.

\begin{tabular}{|c|c|c|c|c|c|c|c|c|}
\hline \multirow[b]{3}{*}{ Testemunha } & \multicolumn{4}{|c|}{5 dias } & \multicolumn{4}{|c|}{8 dias } \\
\hline & \multicolumn{2}{|c|}{ Sem Basalto } & \multicolumn{2}{|c|}{ Com Basalto } & \multicolumn{2}{|c|}{ Sem Basalto } & \multicolumn{2}{|c|}{ Com Basalto } \\
\hline & 80,0 & $\mathbf{A a}$ & 80,0 & $\mathbf{A a}$ & 85,0 & $\mathbf{A a}$ & 85,0 & $\mathbf{A a}$ \\
\hline $10 \%$ & 75,5 & $\mathrm{Aa}$ & 81,5 & $\mathrm{Aa}$ & 79,5 & $\mathrm{Aa}$ & 85,5 & $\mathrm{Aa}$ \\
\hline $20 \%$ & 72,5 & $\mathrm{Aa}$ & 72,0 & $\mathrm{Aa}$ & 79,5 & $\mathrm{Aa}$ & 78,0 & Aa \\
\hline $30 \%$ & 79,5 & $\mathrm{Aa}$ & 79,0 & $\mathrm{Aa}$ & 83,5 & $\mathrm{Aa}$ & 85,0 & $\mathbf{A a}$ \\
\hline $40 \%$ & 83,0 & $\mathrm{Aa}$ & 83,5 & $\mathrm{Aa}$ & 85,5 & $\mathrm{Aa}$ & 87,0 & $\mathbf{A a}$ \\
\hline $50 \%$ & 75,5 & $\mathrm{Aa}$ & 82,5 & $\mathrm{Aa}$ & 79,0 & $\mathrm{Aa}$ & 84,0 & $\mathrm{Aa}$ \\
\hline $60 \%$ & 79,5 & $\mathrm{Aa}$ & 81,0 & $\mathrm{Aa}$ & 85,0 & $\mathrm{Aa}$ & 85,5 & $\mathrm{Aa}$ \\
\hline $70 \%$ & 73,5 & $\mathrm{Aa}$ & 81,0 & $\mathrm{Aa}$ & 76,0 & $\mathrm{Aa}$ & 88,5 & $\mathrm{Aa}$ \\
\hline $80 \%$ & 76,5 & $\mathrm{Aa}$ & 76,5 & $\mathrm{Aa}$ & 80,5 & $\mathrm{Aa}$ & 81,0 & $\mathbf{A a}$ \\
\hline $90 \%$ & 75,0 & $\mathrm{Aa}$ & 79,0 & $\mathrm{Aa}$ & 78,0 & $\mathrm{Aa}$ & 81,5 & $\mathbf{A a}$ \\
\hline $100 \%$ & 83,5 & $\mathrm{Aa}$ & 85,5 & $\mathrm{Aa}$ & 87,5 & $\mathrm{Aa}$ & 87,0 & $\mathbf{A a}$ \\
\hline \multirow{2}{*}{\multicolumn{3}{|c|}{$\begin{array}{l}\text { CV (\%) } \\
\text { Desvio Padrão }\end{array}$}} & 7,93 & & & 6,92 & & \\
\hline & & & 6,26 & & & 5,75 & & \\
\hline
\end{tabular}

Médias seguidas da mesma letra maiúscula na coluna não diferem estatisticamente.

Médias seguidas de mesma letra minúscula na linha não diferem estatisticamente.

A camada de adesivo utilizada no recobrimento das sementes parece não ter exercido efeito nocivo sobre as trocas gasosas e a absorção de água pelas sementes, processos importantes uma vez iniciada a germinação e a emissão da radícula (SANTOS, 2016). Por isso a tomada de decisão na escolha de adesivos de alta colagem como o PVA, deve ser embasada nos efeitos que possam causar à fisiologia da semente. Esta pressuposição foi objeto de estudo, cuja metodologia de diluições possibilitou testar os efeitos deste adesivo em sementes de feijão miúdo, 
motivado por resultados de pesquisas em sementes de outras culturas como braquiária (Brachiaria brizantha (Hochst.) Stapf.) e alface (Lactuca sativa L.), que não apontaram adversidade deste mesmo adesivo sobre a qualidade fisiológica das sementes (SILVA et al., 2002; SANTOS et al., 2010).

\section{CONCLUSÃO}

O método de semeadura com saraquá foi eficiente para determinar a aderência do recobrimento das sementes de feijão miúdo com pó de basalto. Concentrações de acetato de polivinila (PVA) acima de $60 \%$ podem ser utilizadas como adesivo em sementes de feijão miúdo sem haver grande perda do pó de basalto do recobrimento. $O$ adesivo a base de acetato de polivinila (PVA) pode ser utilizado como uma alternativa no recobrimento de sementes de feijão miúdo com pó de basalto.

\section{REFERÊNCIAS}

ARTUR, A. G.; OliVEIRA, D. P.; COSTA, M. C. G.; ROMERO, R. E.; SILVA, M. V. C.; FERREIRA, T. O. Variabilidade espacial dos atributos químicos do solo associada ao microrelevo. Revista Brasileira de Engenharia Agrícola e Ambiental, v. 18, n.2, p.141-149, 2014. Disponível em: <http://dx.doi.org./10.1590/S1415-43662014000200003>. Doi: 10.1590/S141543662014000200003.

BEVILAQUA, G. A. P.; EBERHARDT, P. E. R.; JOB, R. B.; PINHEIRO, R. A.; RODRIGUES, R. C. Produção de biomassa e de sementes, qualidade bromatológica e fixação de nitrogênio em feijão-sopinha. Cadernos de Agroecologia, v.8, n.2, p.2236-7934, 2013. Disponível em: <file:///D:/Meus\%20Documentos/Downloads/digitalizar0013.pdf>.

BRASIL, Ministério da Agricultura, Pecuária e Abastecimento. Regras para análise de sementes. Ministério da Agricultura, Pecuária e Abastecimento. Secretaria de Defesa Agropecuária. Brasília: Mapa/ACS, p.345-347.2009.

BRASIL. Lei no 12.890 de 10 de dezembro de 2013. Disponível em: <http://www.planalto.gov.br/ccivil_03/_Ato2011-2014/2013/Lei/L12890.htm>. Acesso em: 10 maio 2017.

CAMARGO, C. K.; RESENDE, J. T. V.; CAMARGO, L. K. C.; FIGUEIREDO, A. S. T.; ZANIN, D. S. Produtividade do morangueiro em função da adubação orgânica e com pó de basalto no plantio. Semina: Ciências Agrárias, v.33, s.1, p. 2985-2994, 2012. Disponível em: <http://dx.doi.org/10.5433/1679-0359.2012v33Supl1p2985>. Doi: 10.5433/1679-0359.2012v33Supl1p2985.

COLA, G. P. A.; SIMÃO, J. B. P. Rochagem como forma alternativa de suplementação de potássio na agricultura agroecológica. Revista Verde, v.7, n.1, p.01-08, 2012. Disponível em: <http://www.gvaa.com.br/revista/index.php/RVADS/article/view/1132/1269>.

CONCEIÇÃO, P. M. da; VIEIRA, H. D. Qualidade fisiológica e resistência do recobrimento de sementes de milho. Revista Brasileira de Sementes, v.30, n.3, 
p.48-53,

2008.

Disponível

em:

$<$ https://www.researchgate.net/publication/250036845_Qualidade_fisiologica_e_resis tencia do recobrimento de semente>. Doi: 10.1590/S0101-31222008000300007.

COUTINHO, P. W. R.; SILVA, D. M. S.; SALDANHA, E. C. M.; OKUMURA, R. S.; SILVA JÚNIOR, M. L. Doses de fósforo na cultura do feijão-caupi na região nordeste do Estado do Pará. Revista Agro@mbiente On-line, v.8, n.1, p.66-73, 2014. Disponível em: <http://dx.doi.org/10.18227/1982-8470ragro.v8i1.1310>. Doi: 10.18227/1982-8470ragro.v8i1.1310.

CRUSCIOL, C. A. C.; SORATTO, R. P.; CASTRO, G. S. A.; COSTA, C. H. M.; FERRARI NETO, J. Aplicação foliar de ácido silícico estabilizado na soja, feijão e amendoim. Revista Ciência Agronômica, v.44, n.2, p.404-410, 2013. Disponível em: <http://www.alice.cnptia.embrapa.br/alice/handle/doc/953836>.

EBERHARDT, P. E. R.; RADKE, A. K.; DÖRR, C. S.; ALVES, C. A.; BEVILAQUA, G. A. P.; SCHUCH, L. O. B. Desempenho fisiológico de sementes de arroz recobertas com agrominerais. In: Congresso Brasileiro de Arroz Irrigado 9, 2015, Pelotas. Ciência e tecnologia para otimização da orizicultura: anais. Brasília, DF: Embrapa; Pelotas: Sosbai, $2015 . \quad$ Disponível em: $<$ http://ainfo.cnptia.embrapa.br/digital/bitstream/item/130132/1/Gilberto-AntonioPeripolli-08-254-trab-6-7121-244.pdf>.

FONTES C. S.; CHIAVEGATTO L. F.; ALVES, M. A. Avaliação dos efeitos de higroscopicidade do cloridrato de cisteína nas cápsulas duras. Revista de Saúde, v.3, n.2, p.4-13, 2012. Disponível em: <http://dx.doi.org/10.21727/rs.v3i2.77>. Doi: $10.21727 /$ rs.v3i2.77.

GOTTSCHALL, C. S.; ALMEIDA, M. R. de; TOLOTTI F.; MAGERO, J.; BITTENCOURT, H. R.; MATTOS, R. C.; GREGORY, R. M. Avaliação do desempenho reprodutivo de vacas de corte lactantes submetidas à IATF a partir da aplicação do $\mathrm{GnRH}$, da manifestação estral, da reutilização de dispositivos intravaginais e da condição corporal. Acta Scientiae Veterinariae, v.40, n.1, p.1-10, 2012. Disponível em: <http://www.ufrgs.br/actavet/40-1/PUB\%201012.pdf>.

JAIROCE, C. F.; TEIXEIRA, C. M.; NUNES, A. M.; NUNES, C. F.; PEREIRA, C. M. P.; GARCIA, F. R. M. Insecticide activity of clove essential oil on bean weevil and maize weevil. Revista Brasileira de Engenharia Agrícola e Ambiental, v.20, n.1, p.72-77, 2016. Disponível em: <http://dx.doi.org/10.1590/18071929/agriambi.v20n1p72-77>. Doi: 10.1590/1807-1929/agriambi.v20n1p72-77.

LOPES, O. M. M.; COSTA, L. G.; ASSAD, M. L. A. Solubilização de pó de basalto por meio de vinhaça: variação de $\mathrm{pH}$ e nutrientes disponíveis. Engenharia Ambiental, v.10, n.2, p.175-188, 2013. Disponível em: <file:///D:/Meus\%20Documentos/Downloads/EAPT-2012-988\%20(2).pdf>.

MELO, V. F.; UCHÔA, S. C. P.; DIAS, F. O.; BARBOSA, G. F. Doses de basalto moído nas propriedades químicas de um Latossolo Amarelo distrófico da savana de Roraima. Revista Acta Amazônica, v.42, n.4, 2012. Disponível em: 
59672012000400004.

OLIVEIRA, S. DE; RIGO, G. A.; OLIVO, M. LEMES, E. S.; PEDROSO, C. E. DA S. Avaliação do potencial fisiologico de lotes de sementes de feijão-miúdo. Enciclopédia Biosfera, v.10, n.18, p.575-584, 2014. Disponível em: $<$ http://www.conhecer.org.br/enciclop/2014a/AGRARIAS/avaliacao\%20do\%20potenc ial.pdf>.

SANTOS, F. C.; OLIVEIRA, J. A.; VON PINHO, É. V. DE R.; GUIMARÃES, R. M.; VIEIRA, A. R. Tratamento químico, revestimento e armazenamento de sementes de Brachiaria brizantha cv. Marandu. Revista Brasileira de Sementes, v.32, n.3, 2010. Disponível em: <http://dx.doi.org/10.1590/S0101-31222010000300008>. Doi: 10.1590/S0101-31222010000300008.

SANTOS, S. R. G. Peletização de sementes florestais no Brasil: uma atualização. Floresta e Ambiente, v.23, n.2, p.286-294, 2016. Disponível em: <http://dx.doi.org/10.1590/2179-8087.120414>. Doi: 10.1590/2179-8087.120414.

SILVA, A.; ALMEIDA, J. A.; SCHMITT, C.; COELHO, C. M. M. Avaliação dos efeitos da aplicação de basalto moído na fertilidade do solo e nutrição de Eucalyptus benthami. Revista Floresta, v.42, n.1, p.69-76, 2012. Disponível em: <http://www.bibliotecaflorestal.ufv.br:80/handle/123456789/14990>.

SILVA, J. B. C; SANTOS, P. E.C.; NASCIMENTO, W. M. Desempenho de sementes peletizadas de alface em função do material cimentante e da temperatura de secagem dos péletes. Horticultura Brasileira, v.20, n.1, 2002. Disponível em: <http://dx.doi.org/10.1590/S0102-05362002000100013>. Doi: 10.1590/S010205362002000100013.

TAVARES, L. C.; RUFINO, C. DE A.; BRUNES, A. P.; FRIEDRICH, F. F.; BARROS, A. C. S. A.; VILLELA, F. A. Physiological performance of wheat seeds coated with micronutrientes. Journal of Seed Science, v.35, n1 p.28-34, 2013. Disponível em: <http://dx.doi.org/10.1590/S2317-15372013000100004>. Doi: 10.1590/S231715372013000100004.

TESSARO, D.; MATTER, J. M.; KUCZMAN, O.; FURTADO, L.; COSTA, L. A. M.; SAROLL, M.; COSTA, M. S. S. M. Produção agroecológica de mudas e desenvolvimento a campo de couve-chinesa. Ciência Rural, v.43. n.5, p.831-837, 2013. Disponível em: <http://dx.doi.org/10.1590/S0103-84782013005000036>. Doi: 10.1590/S0103-84782013005000036.

WESTHEIMER, F. H. Rochas ígneas: sólidos que se formaram de líquidos. In. Press, F.; Siever, R.; Grotzinger, J.; Jordan, T. H. Para entender a Terra. 4ª ed. Porto Alegre: Bookman, 2006. P.117-139. 